\title{
Rank Matters: Police Leadership and the Authority of Rank Claire Davis
}

Key words: Police leadership; rank; authority; shared leadership

\begin{abstract}
Dominant discourse conceptualises leadership in the police as a rank-neutral activity. Despite the growing body of academic work in police leadership studies, critical analysis of the influence of rank is largely overlooked. The power and authority of rank has assumed a taken-for-granted and unquestioned status. The authority of rank, however, provides police officers with a powerful framework to understand leadership in the police. Drawing on the findings from 38 semistructured interviews with police officers in a U.K constabulary, this paper problematises conventional understanding of police leadership and theorises the use of rank through the creation of an analytical model, the Situated Authority Model of Leadership. The Model acts as framework for policing scholars and practitioners to critically consider the nuanced relationship between context and authority in police leadership. At a time when police organisations across the globe increasingly seek to adopt collaborative leadership practices, this paper contributes to the evidence base on that challenges of developing alternative approaches to leadership and demonstrates that an appreciation of rank in the experience and practice of leadership is fundamental to the leadership reform in the police.
\end{abstract}

\section{Introduction}

The global police leadership landscape is at a time of significant change. The challenges of austerity and professionalisation have accelerated the pressure to transform police organisational structures and operational working practices (Fleming,2014; HMIC,2017; Holdaway,2017; Neyroud,2011). At the same time, the nature of crime appears more complex; the increasing demand from mental health services, for example, requires specialist police skills and a strong partnership-working 
ethos (de Tribolet-Hardy et al.,2015; van Dijk and Crofts,2017). These factors mean that police organisations need to increase productivity in a climate of diminishing resources. This is set against growing concerns about trauma and stress in policing and a greater emphasis on personal resilience and well-being in the police workplace (Bullock and Garland,2018; Hesketh et al.,2005; Smith and Charles,2015). This accumulative demand on police leaders is unprecedented. Police leaders across the globe are required to understand and develop their leadership to effectively support their staff in an environment of escalating demand and economic and organisational uncertainty. Against this backdrop therefore, over-dependence on traditional approaches to police leadership is increasingly recognised as outdated (Caless and Tong,2015; Herrington and Colvin,2016; van Dijk et al.,2015).

Leadership theorists emphasise the importance of understanding leadership as a shared, collaborative, social process (Chaleff,2009; Fletcher and Kaufer,2003; Kelley,1992). Shared leadership is based on assumptions of collectivity, collaboration and participation (Gronn,2002; Pearce et al.,2008). These principles, however, conflict with traditional working practices in the police and the adherence to the quasimilitaristic rank structure (Craig et al.,2010; Steinberger and Wuestewald,2008). The hierarchy represents a formal organising mechanism, reinforced by legislation, to distribute leadership authorities of responsibility, accountability and decision-making by rank. Hierarchical leadership practices are understood to stifle collaboration, innovation and challenge (Andersson and Tengblad,2009; Cowper,2004). We have seen various attempts to reform the police hierarchy in the UK, a trend also captured, for example, in empirical work in Australia (Fleming and Lafferty,2000) and South African police organisations (Fleming and Marks,2004). Despite these attempts, the rank structure, and the quasi-military style of leadership, remain largely intact (Adlam,2002; Savage,2003; 
Silvestri,2011). The endorsement of shared leadership therefore neglects to consider the power dynamics of rank. This paper applies the criticality of critical leadership studies to theorise police leadership as a power-laden, rank-centric activity. The paper is structured in two parts. The first part situates the research in the context of contemporary understanding of leadership and power. Conventional discourse is problematised to highlight the power dynamics of rank as an inherent but unexplored area of police leadership studies. Drawing on empirical findings, the second part details the evidence underpinning the Situated Authority Model of Leadership. The paper concludes with a discussion of the implications of the Model for leadership development in the police.

\section{Power and Police Leadership}

Power is an inherent and characteristic feature of leadership (Burns, 1979; Gardner,1990). Leaders have power over resources, decision making, rewards and sanctions, hiring and firing (Collinson,2014; Kort,2008). In policing, there is a strong attachment to centralisation of power at senior ranks and dualistic power relationships between senior and junior officers characterised by distance and tension (Mastrofski,2002; Punch,1983). Police leadership is performed in a rank-based culture which constructs and reconstructs conventions of 'know your place' and 'rank knows best' (Adlam,2002; Silvestri,2011). Power is assumed as unproblematic and uncomplicated (Collinson,2011; Gordon,2002). The conformity of junior officers is normalised as a demonstration of effective leadership, whilst resistance is problematised and regulated (Collinson,2012). Senior police leaders are positioned as causal agents of change and initiators of action, whilst junior officers are conceived as passive recipients (Crevani et al.,2010; Meindl,1995; Shamir,2007). Critical leadership theorists challenge the powerful/powerless dichotomy of conventional discourse and examine the situated 
nature of power in leadership (see Collinson,2014; Fletcher,2004; Ford,2010; Gordon,2002; Grint,2010; Tourish,2013).

This criticality however is yet to transform the dominant discourse of leadership in the police. The police occupational culture literature illustrates the tensions between policy rhetoric of senior management and the lived experience of the rank-and-file, and the power of junior officers to resist managerial influence (Chan,2007; Haake et al.,2017; Holdaway,1977; Loftus,2009; Reuss-Ianni,1983; Skogan,2008). Whilst there is some recognition that the meanings assigned to rank are powerful in defining credibility and legitimacy in leadership, how power is exercised and sustained, negotiated and resisted is largely overlooked (Rowe,2006; Silvestri,2011).

This research responds to a call for greater inclusion of qualitative research in police leadership and applies the criticality of critical leadership studies by investigating leadership within a social constructionist framework. Leadership in different contexts was considered to uncover the taken-for-granted beliefs about the nature of police leadership. The power of rank to inform the understanding and experience of leadership emerged in the analysis. Based on the findings of the 38 semi-structured interviews, the Situated Authority Model of Leadership was developed as a framework to capture how police officers exert, negotiate and resist the authority of rank in leadership.

\section{The Study}

This research is based on a case study of one U.K. police constabulary to access rich, in-depth data on the understandings and experiences of leadership (Schofield,1993; Stake,1995). The research constabulary is a county police force in England and Wales, comprising of over 1,500 police officers. At the time of the research, the chief constable had been in post for two years, with a history of service with the constabulary. The selection of the constabulary was informed by two fundamental principles. First, the 
maximisation of learning (Stake,1995). The constabulary, not unlike other constabularies in England and Wales, has undertaken a collaboration programme to jointly deliver key leadership and management functions. This provided an opportunity to explore the synergy and tensions in leadership.

Second, research practicalities, particularly in terms of research access (Schofield,1993; Stake,1995; Ostrander,1995). Access for this research was secured at chief constable rank. In the early stages of this study, several meetings with the chief constable were conducted to discuss the focus and scope of the research. The constabulary was offered an executive summary of the research findings and presentations to disseminate the findings to police officers as part of the 'research bargain’ (Becker,1970; Van Maanen,1978).

Research access at chief constable level presents characteristic challenges when securing informed, voluntary consent, as junior officers may feel obliged to participant in the research (Norris,1993; Skinns et al.,2016). Careful consideration of power dynamics, and the extent to which junior officers feel able to 'opt out' of the study, is therefore important (Gravelle,2014; Rowe,2007). All participants were provided with a Research Briefing and contacted prior to the interviews, where the purpose and scope of the research was discussed and their right to refuse to take part was explained. These early discussions were crucial in building trust and rapport. Assurances of confidentiality and anonymity were also important; the truthfulness of junior officers, for example, may be affected if they think the research findings will be reported back to senior management (Gravelle,2014; Skinns et al.,2016). Anonymity is challenging however in the context of interviewing senior police officers and the identifiable nature of their role (Mikecz,2012; Phillips,1998). Participants were therefore allocated to the sample groups of senior management (chief officers), middle management (chief 
superintendent and superintendent) and lower management (chief inspector and inspector). Direct quotes were assigned to sample groups and further identifiable features, such as gender or role, were not included to protect the anonymity of participants.

The fieldwork for this research was divided into two phases; the scoping phase and the main interview phase. The purpose of the scoping phase was familiarisation of the research site and to inform the interview guide (Brown,1996; Van Maanen,1978; Ostrander,1995). The scoping phase consisted of six scoping interviews with police inspectors and sergeants and observations of six shifts with PCs and sergeants, which were conducted five months before the main interview phase. Preliminary analysis incorporated emerging insights from the scoping phase into the interview guide for the interview phase (Charmaz,2014). For example, police officers in the scoping phase spoke about a newly formed team, which had a remit to review the constabulary's structure and processes in the context of austerity, as a mechanism of consultation and challenge. This was explored further in the interview phase in terms of the experience of leadership and the 'meaningfulness' of the process. The scoping phase was therefore an essential preparatory stage. The knowledge gained was valuable in establishing the credibility of the research (Van Maanen,1978), securing informal research access (Gravelle,2014; Loftus,2009) and readdressing the imbalance when interviewing people in positions of power (Mikecz,2012; Ostrander,1995; Richards,1996).

In the main interview phase, 38 semi-structured interviews were conducted with chief constable to inspectors over a three-month period beginning in September 2015. The interviews lasted between one and two hours, averaging around 1.25 hours. Participants were sampled to capture the influence of rank in police leadership; 6 chief officers (senior management), 11 officers at the superintendent ranks (middle 
management) and 21 at the inspector ranks (lower management) were interviewed. The vast majority (37) of interviews were audio-recorded and these were later transcribed verbatim producing over forty-five hours of transcriptions. The research sample incorporated a balanced mix of participants in terms of gender ( 25 male and 13 female) and role (28 uniformed and 10 non-uniformed), which was largely reflective of the make-up of the constabulary at the time of the research.

The analytical strategy was an inductive approach focusing on the primacy of 'emergence' (Charmaz,2014). The analysis progressed through three main phases; fieldwork, coding and theorising. In the fieldwork phase, emerging insights were documented after each interview, followed by a summary of main points at the end of each interview day and a consolidation of insights at the end of the fieldwork. The process in the coding phase was iterative and comparative based on the principle of 'systematic doubt' to manage preconceptions and potential bias (Agar,2008;

Charmaz,2014). NVivo 10 was used to support the analytical coding. The first stage in the coding phase was 'full coding' in which interview transcripts were coded line-byline and a descriptor was assigned to the data that related closely to the subject being discussed. The focus of this stage of coding was definition and produced descriptive codes, such as 'caring for welfare' or 'asked opinions'. The second stage of coding was 'thematic coding' and involved the interrogation of the initial codes to organise them into thematic groupings. This analytical stage focused on meaning rather than description and consequently produced conceptual codes. The descriptive code of 'asked opinions' for example became a sub-category within the conceptual code of 'consultative'. The final stage of analysis, theorising, involved the interrogation of the conceptual codes to produce a conceptual model. This inductive approach and analytical 
openness were crucial in situating the meanings and understandings of police officers as central to the construction of leadership.

A relationship between leadership and the use of rank as an authority emerged in the analysis. This relationship is conceptualised in the Situated Authority Model of Leadership. In the Model, the concepts of 'doing' and' undoing' of rank are used to reveal the activity involved in the management and negotiation of authority in leadership.

\section{The Situated Authority Model of Leadership}

Studies of police leadership have typically paid insufficient attention to the influence of the occupational context (Adlam,2003; Cockcroft,2014). Leadership is highly sensitised to social context and social relationships (Bryman et al.,1996; Biggart and Hamilton,1987). Rank was the dominant narrative in police officers' discussions of leadership and specifically the ways in which differential authority informs the interactions between junior and senior officers. Rank provides a powerful framework for police officers to understand what leadership is and how it ought to be performed. Rank is meaning-making, leadership practices are defined as appropriate and legitimate through the 'lens' of rank (Grint,2005; Smircich and Morgan,1982; Pye,2005;

Weick,1995). Police officers at all ranks spoke repeatedly about the influence of rank through the discourse of 'presence' and 'performance' of rank; police officers, for example, used descriptions such as "carrying rank", "wearing of rank" or "handle the rank" in their discussions:

"I don't think it's the rank that's the issue. I think it's individuals within that, you know, you've got the stuff on their shoulders but it's how they choose to carry it" (Middle Management, Interview 27). 
The Situated Authority Model of Leadership captures the negotiation of rank as an authority using the concepts of 'doing' and 'undoing' of rank. The doing of rank describes the heightened presence of rank and situations which prioritise the hierarchical structure. In these situations, rank can be used as a resource to facilitate leadership and the authority is perceived as necessary to 'get things done'. In contrast, the undoing of rank describes the ways in which its presence is mitigated or challenged. In these situations, rank was perceived as a barrier rather than a resource and therefore the presence of rank was downplayed. The Situated Authority Model of Leadership situates the use of rank in the context of 'audience' and 'risk' to illustrates how police officers use rank relative to their understanding who is watching and what is at risk.

Figure 1: $\quad$ The Situated Authority Model of Leadership

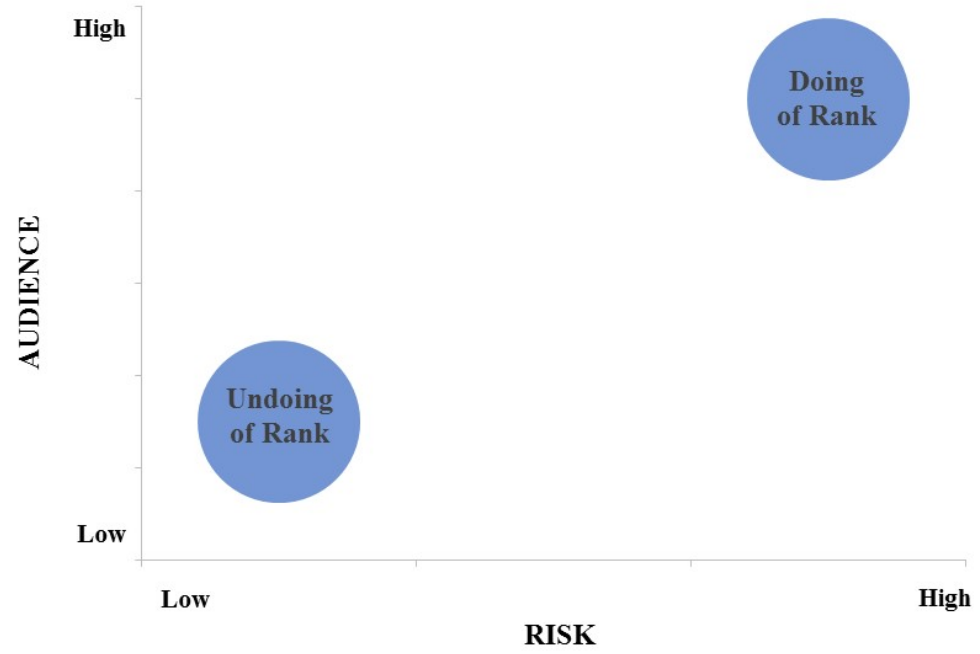

\section{Audience}

Police officers at all ranks described different, at times competing and contradictory, 'audiences' and the ways in which these audiences inform their 
leadership practices. In the Situated Authority Model, audience is conceptualised as 'low' and 'high' audience situations.

Low-audience situations are understood to be protected spaces, hidden from public view where there are no 'outsiders' to observe the leadership interactions. The most common example identified is an informal, one to one exchange between a junior and senior officer, often taking place behind the closed doors of an office. This is perceived as a low visibility, safe space. Whilst the differential authority is present because the officers involved are not rank-equals, the 'performance' of rank is not necessary. The majority of police officers discussed this space as one where the conventions and assumptions assigned to rank, such as the reluctance to challenge or question senior officers, can be subverted or challenged. In low-audience situations therefore, the undoing of rank is possible:

\footnotetext{
"So, if I had a one to one with the chief, or [they] came out and met me, I would ask [them] questions and I wouldn't be worried about challenging ... I know [they're] open to challenge, and if it's a one to one, I would" (Middle Management, Interview 25).
}

High-audience situations are understood as public encounters, highly visible spaces, typically involving 'outsiders' and often powerful outsiders. Police officers discussed public accountability forums with the Police and Crime Commissioner as an example of this type of situation. The conventions and formalities of rank are clearly adhered to and the performance of rank is most obvious. Whilst there is an openness to challenge upwards in low-audience situations, there is a strong resistance to these expressions in public forums. In high-audience situations therefore, the doing of rank in leadership is considered most appropriate: 
"I wouldn't question a chief constable in a public forum, a sergeant might not choose to question a superintendent in a public forum. So, rank definitely plays out in the police, in public especially. Things like that wouldn't happen" (Middle Management, Interview 10).

\section{Risk}

Police officers also understood situations in terms of risk and these perceptions similarly informed the understanding of the leadership required in that situation. Risk was discussed in the interviews as threats to the public, personal safety, safety of police colleagues and reputational risk to the police force. In the Situated Authority Model, risk is conceptualised as low-risk and high-risk situations. Police officers drew on narratives of time to differentiate high and low risk situations.

Low risk situations were perceived as low threat to the public or officer safety and low reputational risk. Time is understood as a protective factor; low risk situations are associated with the longer-term and less urgent aspects of police work. In low risk situations, the authority of rank is not necessary to 'get things done quickly'. These situations are considered safe to challenge traditional conventions, and therefore, facilitate greater autonomy:

\footnotetext{
“That's a good example, she's a beat manager, so she's responsible for [area] so she's, as far as I'm concerned, and she's concerned, she's the primary problem solver for [area]. She's got a problem pub, drug taking, anti-social behaviour, violence and disorder. She's called the meeting with the licensing panel, she's called the meeting with the licensee, she's come in now and suggested the tactical options, and I've given her some reassurance that she's on the right line, great" (Lower Management, Interview 11).
}

High risk situations were understood as critical, emergency situations, public order and firearms incidents were the most common examples cited. In these situations, there is a strong attachment to the rank structure, which is perceived as useful in 
providing a clear demarcation of roles and responsibilities and a clear allocation of decision making. The centrality of the rank structure in high-risk situations shapes the expectations of leadership in that environment. These situations are perceived to warrant command-based leadership where authority of rank is overtly used. Rank therefore is highly present in these situations, the rank structure is relied upon to organise leadership:

\begin{abstract}
"If you went into firearms they are all very, very rank and hierarchical so if they want something they will go to Sergeant, Sergeant will go to Inspector, the Inspector will go to the Chief Inspector” (Senior Management, Interview 33).

"There are times in operations and particularly things like riots or firearms jobs where you need the discipline of almost the how high do you want me to jump on the way up. So, [as a PC] sergeant says to me 'You have got to jump' you say 'yes of course' and off you go" (Senior Management, Interview 7).
\end{abstract}

Time was the main determinant in understanding risk; the sense of urgency is a characteristic of high-risk situations. The structure and authority of rank is relied upon therefore to facilitate urgent action:

\begin{abstract}
"If you have a major incident, you know, a significant incident on the ground where you need people to do things quick time, that's when that [rank] side of it really kicks in. Because it's like, there ain't no time for asking a question. I'm taking the direction, this has got to be done, because there's a risk there, so you'd have to direct people quick time and I think that's where it then kicks in. You've got to have that control of that structure around deploying your resources in quick time. Because when you've got an incident on-going, there are things that just have to be done." (Lower Management, Interview 15)
\end{abstract}

There is a clear attachment to the importance of the rank structure in high risk situations, the authority of rank is a mechanism for 'doing' leadership. The 'doing of rank' in leadership in these situations is therefore most evident. 


\section{Doing of rank}

The doing of rank in leadership, most necessary in high-risk and high-audience situations, describes the heightened influence of rank. There are symbolic representations of rank inherent in the police, such as the police uniform or verbal reference to rank through 'sir' or 'ma'am', which situate rank 'within' interactions between senior and junior officers. In the doing of rank, behaviours closely adhere to the conventions of 'rank etiquette' underpinned by notions of formality, discipline and respect. Rank provides 'codes of order' (Goffman,1959) or 'deep structures'

(Gordon,2002) which convey and reinforce differential relations of authority and inform behaviour between senior and junior officers. There is a strong attachment to the doing of rank, it is a fiercely protected aspect of police leadership and represents conventional practice; police officers, for example, described the 'positioning' of individuals by rank as something you 'get used to' to the extent that it becomes 'invisible'. In the doing of rank in leadership, rank can also be used as a 'display for persuading the audience' (Goffman,1959). The doing of rank describes the ways in which the structure and authority of rank is used as a resource in leadership 'to get things done', such as the 'pulling' of rank.

The doing of rank was particularly evident in assumptions related to decision making. Legitimacy of decision making was not perceived as equally distributed across the organisation but rather assigned on the basis of seniority of rank. Senior officers were assumed as trusted and skilled decision-makers. In high-audience and high-risk situations, this was often justified and valued as operational necessity; rank provided quick decision making with clear lines of responsibility and accountability. Outside of operational situations, chairing meetings was discussed. The role of chair was typically performed by the most senior ranking officer, and consequently, positioned senior 
officers as the coordinator, decision maker and 'in charge' of the meeting. In the doing of rank, decision making in leadership therefore clearly relates to rank:

"You've got to have somebody who's prepared to ultimately make the decision. And I think, you know, the rank structure allows and affords in a spontaneous situation to have that decision making. We're used to making decisions with a lot of risk attached to it, and actually, one thing that we're pretty good at is, when it's risky, we're prepared to go 'that actually now demands a decisive action'. Because you want to know somebody is sitting in the seat who's actually going to get on and go through it all and decide. People are comfortable then, they're almost reassured. Rank is known for the organisation as decision making" (Lower Management, Interview 13).

The authority and structure of rank is used to facilitate decisions and allows for the organisation of responsibility and accountability. In positioning senior officers as trusted decision makers, this encourages a command-based approach to leadership:

"You've got to think about only certain positions have responsibility for things when they happen, so we have a rank structure, so we have certain places that we have to fill... The service does need people who say, 'just do it', because there is going to be a time where we'll ask people to do things that are a bit s***y, a bit against what they want to do, but it does still need to be done and quite timely" (Lower Management, Interview 29).

In the doing of rank, decision making was clearly positioned 'upwards' and this provided a sense of protection and reassurance, referred to by police officers as "top cover". Police officers, particularly in the lower and middle management ranks, discussed the conventions of 'reverting back' to the rank structure to keep senior officers informed 'just in case':

"It's like they think, 'there's a decision to be made here, I really should make it, but just in case I get it wrong, I'll copy in my boss because they'll tell me if it's wrong'. And we've got a bit of that culture. I honestly get 80 to 130 emails a day, 
30 probably are for me, so most of them are cc emails, 'just to let you know' from my staff, so 'you're the boss just to let you know'.... Nobody wants to get one wrong and if you spread the blame or spread the pain as much as you can, you're making it less damaging for yourself as an individual. We're very risk adverse...No one wants to make a wrong decision, so you keep checking" (Middle Management, Interview 21).

This reverting back to the rank structure highlighted notions of risk and consequences of making mistakes. In this context, decision making by rank was understood as protective, a way to manage the perceived risk of making the 'wrong decision'. If decisions are clearly located at particular ranks, in other words, the location of accountability is similarly clear. Particularly for police officers in the lower management ranks, rank therefore is used to manage perceived risk:

\footnotetext{
"It's like, it gives you top cover, a chief superintendent here talks about top cover, and it's absolutely right, if I have to make a difficult decision, you know, decisions with risk, no-win situations. So, it's a bit like that. The sergeant on the scene being able to say to an inspector in here, there's two ways of handling this, what do you think? He's passed on that responsibility to someone who's paid more to make that decision. So that top cover's really important, and when you're dealing with, like we are, threat and risk and vulnerability all the time, you've got to make those difficult decisions, and being able to go to someone who can steer you on it, and they take the decision off you because they're paid more, can be quite reassuring and comfortable, and we're generally comfortable with that" (Lower Management, Interview 20).
}

Underpinning decision-making practices are assumptions of knowledge and competence. In assigning decision making by rank, the primacy is placed on rank rather than knowledge or expertise. Knowledge or competence is not understood therefore as independent of rank but rather through the 'lens' of rank. Police officers, particularly at the middle management ranks, spoke of assumptions that senior officers have achieved their position through accruing experience and demonstration of competence: 
“Ultimately people who've got to that level of rank within the service have put the effort in, they'd have done the exams, some of them will have quite a weight of service behind them as well, some people have done really well and got very high up very quickly, but ultimately, they have that service with them" (Lower Management, Interview 3).

In the doing of rank, interactions and behaviours clearly align with the conventions of rank. Competencies are assigned to rank, such as decision making, responsibility and knowledge, and this affords junior officers with the protection and reassurance of 'top cover'. Rank has protective functions; police officers in the middle management ranks for example referred to the rank structure as 'filtering' pressures and as a 'shield' or 'buffer' between more senior officers and their teams. The positioning of decision making by rank is justified by police officers through understanding the situation as high-risk and high-audience, critical incident management, for example, requiring clear and structured lines of accountability and quick decision making. Emphasis is placed on the demarcation and separation of rank in leadership therefore. Rank is used a resource to 'get things done' which is indicative of a command-based, top-down, directive approach to leadership.

In contrast to the doing of rank, the analysis revealed that rank was also understood by police officers as barrier in leadership. The authority of rank informs interactions between junior and senior officers in a way that 'disrupts' leadership. Consequently, police officers sought to manage and subvert the influence of rank.

\section{Undoing of rank}

The undoing of rank describes the ways in which the authority of rank in leadership is navigated to challenge the over-reliance on rank in leadership. Police officers, particularly at senior management rank, expressed a sense of 'being careful' 
with the authority of rank through phrases such as "use it wisely". There is an awareness therefore of the disruptive influence of rank in leadership:

"But that, that for me is probably one of the most important things of leadership, is understanding the effect that your position has on people in a different section from you ... you have had to come to terms with the impact that this, the impact that what's on your shoulders has and it's not, I think you can be the person you are, you either enhance that and you make it even more powerful than it already is, but don't ever underestimate the power of what's on your shoulders" (Senior Management, Interview 38).

Low-risk and low-audience situations, which were perceived as safe and protected spaces, allow for the presence of rank to be navigated, expectations of rank are situationally suspended or 'knowingly contradicted' (Goffman,1959). The undoing of rank typically involved articulated moments or situations; situations were designated as 'safe' or 'informal' through verbally defining it as such. This is captured below, with reference to "shoulders off" conversation as recognition of the influence of the epaulettes on the police uniform:

"There is actually a time for that to flatten [the rank structure] and that's what I try and do at work, I try and create, you know, when we say, 'shoulders off', we just have a straightforward talk, what is actually going on? You know, because it's very much like 'don't tell the boss', well actually, I don't want that, because it doesn't help me. And I've said that to shifts, I don't want this dressed up please, I just want to know what you're actually thinking" (Lower Management, Interview 13).

In one-to-one situations, police officers, particularly in the middle management ranks, spoke of providing their staff with 'permission' to refer to them by their first names rather than by their rank. The demarcation of rank is minimised and as such the authority of rank is less disruptive. These acts illustrate the 'framing' or 'management' of situations (Pye,2005; Smircich and Morgan,1982) as 'rank-neutral'; rank is present, 
as police officers involved are not rank equals, but these actions seek to manage the influence of differential authority in leadership:

"I am forever saying to people 'Call me [name]' .. [the rank] almost psychologically causes you to behave differently, but no I do try really hard to get people to, you know, get to know people... I think we would work better if we could actually tone that down a lot, and some people can do it and others can't... and actually talking and interacting as a team for me is far more powerful in terms of that, the product that you can come up with" (Senior Management, Interview 9).

The undoing of rank draws on notions of accessibility, inclusivity, authenticity and informality. There is a sense of 'sameness' and equality, emphasis is placed on the shared identity as a police officer rather than difference, separation and demarcation by rank. Difference between the ranks is downplayed by focusing on the shared sense of purpose, a sense of team and the person 'behind' the rank.

"Just because I am a [rank], it doesn't make me any better than anyone else. It makes me the same as everyone else, we're all police officers" (Lower Management, Interview 1).

"I would always leave with 'look, I am [rank] but we're all part of the same team, we've just got different roles. Your voice and your opinion is as equally valid as mine, so don't ever think you can't engage with me and for us not to have a dialogue'...We're one team. But you constantly have to do that, constantly have to do that, because you're fighting against that culture, the old culture. It does get in the way" (Middle Management, Interview 30).

"It's really difficult to humanize yourself...There is a wariness though, it is, you can see it, it's bizarre, you can see it in their face" (Middle Management, Interview $10)$.

The removal of rank is understood to create more 'open' or 'genuine' or 'authentic' dialogue between junior and senior officers. Conventional beliefs and 
assumptions about rank are challenged and alternative types of leadership are possible. Consequently, the undoing of rank facilitates more participatory leadership activity through, for example, seeking junior officers' opinions and contributions. Decision making in the undoing of rank is constructed as shared, rather than assigned to the most senior ranking officer, and there is an appreciation of different perspectives and challenge. Situations, moments and experiences are constructed to facilitate 'influence upwards'. There appeared greater recognition of diversity of skills and knowledge with less emphasis on rank as a determinant factor:

"I think on a more personal note, my team's views are really important, so I would consult with the team about decisions we make, as a command or as a department, and make sure they're involved in the decision making, create that environment... it's not just about my views because I'm a higher rank" (Middle Management, Interview 22).

"We need to allow people to create their, you know, their personal style. I don't have a problem with the fact that we are all different, we should all be different, but it starts to create that environment where we will all have to be the same, and I think that is why we end up with, you know, Sergeant X looks like Sergeant Y ... We need different characters, different ways of thinking" (Senior Management, Interview 33)

In the constabulary, various communication mechanisms were used to bypass the rank hierarchy, facilitate shared decision-making and consultation, and present the senior management team as accessible and open to challenge. Blogs from the chief constable and 'Ask the Chief' email portal were typical examples; these were discussed as 'humanising' senior management, removing the barrier of rank open senior management to new ideas from junior officers. Police leaders seek to create a 'rank- 
neutral' tone with their teams or in meetings, drawing on notions of equality and mutuality:

\begin{abstract}
"You know, not rank specific in this team ... We are all level-playing fields, everyone in the team gets that, are you going to be comfortable with it because we are all in it together? We are a small... any small team I've worked in I always found if you got, you know a group of people who are all trying to get the same goal then actually sitting in a room like we are now and somebody call you sir or ma'am, it's just really not going to work... when you are sat in an office and you are all trying to solve the same problem then you know you just don't need all that rank. You know you want those people in that room to be able to challenge... and they don't want to do that if they think that somewhere there is this barrier of rank there" (Middle Management, Interview 25).
\end{abstract}

\footnotetext{
"We need to capture everybody's thoughts and ideas. You know, there's no monopoly on good ideas, and often, the people who are in more senior positions with rank, won't have knowledge of the detail they would need, you need to draw on the people who have very detailed understanding of certain aspects" (Senior Management, Interview 8).
}

In the undoing of rank, the experience of authority in leadership is 'managed', attempts are made to navigate the ways in which rank 'gets in the way' (Silvestri,2011). Whilst differential authority exists, the performance of rank is downplayed. Lowaudience and low-risk situations, perceived as safe and protected, provide permission for this undoing of rank. The authenticity and 'meaningfulness' of attempts at undoing, however, is an area of considerable challenge and resistance. The influence of rank, although minimised in these environments, is not dissolved completely. Differential authority by rank is maintained; rank-neutral perhaps, but not rank-free. Importantly, the authority of rank is required to define the situation as rank-neutral. Junior officers, for example, cannot decide to call a senior officer by their first name without prior 
permission. The situations of undoing still 'contain' the authority of rank therefore, which highlight the tensions and complexities in the navigation of rank in leadership.

\section{The Situated Authority Model: Implications and Critique}

This research explored police officers' understandings of leadership in the police and depicted these understandings in the Situated Authority Model of Leadership.

Taken-for-granted beliefs about rank have a powerful influence on leadership, credibility and legitimacy in leadership is framed through understandings of rank. The Situated Authority Model provides an analytical framework to consider how differential authority is experienced, enacted and negotiated in leadership. The Model positions context as central in the experience of leadership through concepts of audience and risk. This furthers Grint's (2005:1471) argument that those studying leadership should "begin to consider not what is the situation, but how it is situated".

The production of a model to depict complex social relationships is inevitability reductionist (Collinson,2014; Crevani et al.,2010; Reddin,1977). The concepts of doing and undoing of rank represent ideal types, a synthesis of behaviours and assumptions, to capture the relationship between rank, leadership and context. The police working environment, however, is a fragmented and contested space characterised by tension and opposition (Cockcroft,2007; Niederhoffer,1967; Punch,1983; Reuss-Ianni,1983). Likewise, leadership is not a coherent or static experience but an emergent, fluid, discursive and negotiated process (Collinson,2006; Raelin,2011; Tourish,2014; Wood and Ladkin,2008). Whilst the doing and undoing of rank are positioned in the Model as a dichotomy, as distinct and separate entities to allow for comparisons between the different ways rank is used, they are not mutually exclusive categories. Rather, rank 'weaves' in and out of interactions and experiences; its presence is fluid, its authority is respected and resisted, exploited and managed. The experience of authority in the 
workplace, in other words, is not fixed (Andersson and Tengbald,2009; Davies and Thomas,2004; Gordon,2002; Hosking,1997). The Model also depicts the influence of context using audience and risk, this however is not intended as causal or deterministic. Low risk and low audience situations, for example, do not guarantee rank-neutral practices but rather facilitates an opportunity for them, to 'do' leadership differently. The doing and undoing of rank as theoretical concepts are indicative of how authority is enacted and experienced in the police organisation. The purpose of the Model therefore is to provide a 'productive counterassumption' (Alvesson and Svenningsson,2003) which challenges the invisibility of rank in the dominant discourse by positioning rank as central to the experience of leadership in the police.

The reliance and emphasis on rank in the doing of rank is a fundamental barrier to the responsibilization of the police workforce (see Garland,2001). There are increasing calls for police organisations globally to move away from centralised command and control leadership towards the sharing of responsibility captured in the undoing of rank (Rogers,2015; van Dijk et al.,2015). Beliefs associating decisionmaking and knowledge with rank means that skills and experience are neglected in favour of power-centric practices aligned with the rank structure. The acceptance of shared leadership in the police therefore relies on fundamental transformation of traditional working conventions and arrangements (Craig et al.,2008; Gordon,2010; Steinberger and Wuestewald,2008). The primacy of rank over competence conflicts with strategies to empower the police workforce and the capacity of junior officers to 'influence up'. Tourish (2013:5) alludes to the challenges of strategies of responsibilization in hierarchical organisations, he argues:

"If power corrupts then the same might be said of powerlessness. It corrodes our ability to act purposively, take responsibility for our actions and manage our own destiny". 
Low-risk and low-audience situations represent an opportunity, not always utilised, to manage the influence of rank in leadership. In a hierarchical organisation, these low-risk and low-audience situations allow for leaders to suspend traditional topdown leadership in favour of a more collaborative approach. Herrington and Colvin (2016) note the use of innovation laboratories in an Australian police department, where shared leadership emerges. The concept a safe and protected environment is evident in leadership outside policing. In higher education, for example, Whitchurch (2008:379) describes a 'third space' of mixed teams, where organisational structures and conventions are bypassed. These environments facilitate the development of alternative approaches to leadership. Police organisations would be well placed to consider further development of low-audience and low-risk situations to facilitate shared and collaborative leadership. Both hierarchical and shared leadership practices in the police may, in other words, be possible (Carson et al.,2007).

Contemporary demand challenges the traditional working practices in police organisations across the globe, and importantly, the dominance of the doing of rank in leadership. Police officers can no longer continue to rely on the authority of rank to 'get things done', situations of undoing rank in leadership are increasingly necessary. The professionalisation reforms, in particular, intensify the need for police officers to understand their leadership. The Situated Authority Model provides police leaders with a framework for critical reflection of how they use rank in their leadership and how their authority is experienced by junior officers. The Model provides police leaders with a deeper understanding of their leadership, greater self-awareness and equips them to challenge the barrier of rank in their leadership. The Model therefore has important implications for embedding critical reflexivity and collaborative decision making in operational practice. 
Police leaders globally, however, are increasingly working in an environment of high risk and high audience. The accountability landscape is at a time of significant change, police leaders are required to negotiate relationships with competing high audiences (Caless and Owens,2016; Fleming,2008; de Maillard and Savage,2018; Lister,2013). The politicalisation of accountability, such as the Police and Crime Commissioners in England and Wales (Newburn,2012), situate powerful high audience political actors within police governance. The rise of social media ensures that the activities of local police leaders are highly visible and scrutinised on a global platform (Bullock,2018; Walker and Archbold,2014). These types of pressures may act as a barrier to the development of alternative, 'risky', leadership practices. The rising global threat of terrorism also legitimatises an increasing emphasis on militaristic, rank-centric leadership practices (Kraska,2007; Waddington,1999). We may observe, therefore, a strengthening of rank-based assumptions in leadership, indicative of the doing of rank, in order to be seen to 'get things done'. At a time when contemporary demand requires police leadership globally to embrace shared leadership practices, these external pressures may result in a greater reliance on rank.

Challenges to the relationship between rank and leadership in the police have typically focused on reforms to the rank structure. The rank structure is not unimportant in police leadership, but an emphasis on structure overlooks the deeply entrenched beliefs about rank as captured in the Situated Authority Model of Leadership. Differential authority is 'rebuilt' and maintained in doing of rank or challenged in protected environments in the undoing of rank. A critical appreciation of rank as an authority, particularly the way rank acts as a barrier to the responsibilization of junior officers, is a crucial precursor to leadership reform. Without sufficient consideration of 
the dynamics of rank, policy aimed to create diversity in leadership will not, therefore, result in diverse leadership practices.

\section{Concluding Considerations}

This paper applied the criticality of critical leadership studies to police leadership and developed the Situated Authority Model of Leadership as the first attempt to depict the nuanced relationship between rank as an authority and leadership. Scholars have long captured the influence of context in leadership (Biggart and Hamilton,1987; Bryman et al.,1996; Grint,2005). Understandings of the situation, captured in the Model through audience and risk, legitimise ways of using rank. In highaudience and high-risk situations, there is reliance and emphasis on the rank structure compared with low-audience and low-risk situations which create an opportunity to conventional assumptions and facilitate shared leadership.

The problem of 'generalisability' of case study research, the challenge to satisfy traditional positivist standards of generalisation based on knowledge as neutral and context-free, are well-documented (Cronbach,1975; Hammersley,2012; Lincoln and Guba,2000; Schofield,1993). Yet we understand social interaction and behaviour, and consequently leadership, to be highly sensitised to context (Blumer,1969; Grint,2005; Goffman,1959). The investigation of 'the particular' (Gomm et al.,2000; Stake,1995), the micro-level interactions and experiences, is fundamental to studying leadership as a dynamic socially constructed, context-dependent process (Alvesson,2011; Bryman et al.,1996; Grint,2005; Meindl,1995). Case study research has provided a rich appreciation of the meanings, politics, identities in leadership and deepened understanding of the competing and contradictory leadership narratives (see, for example, Alvesson,1992; Andersson and Tengblad,2009; Ford,2006). An alternative approach to generalisation applicable to case study research, that appreciates the process 
by which micro-level experience aids understanding of broader social phenomenon, is therefore needed (Donmeyer,2000; Hammersley,2012; Stake,1995). In appreciating the influence of social context, Cronbach (1975:125) rejects traditional notions of generalisation, arguing that "when we give proper weight to local conditions, any generalisation is a working hypothesis, not a conclusion". Case studies contribute to a cumulative process of learning, application, adaption and refinement (George and Bennett,2005). Leadership is "a highly shaky construction" (Alvesson and Sveningsson,2003:378); any generalisation of leadership needs to appreciate the fragility and fluidity of leadership as a social process. The Situated Authority Model therefore acts as a 'working hypothesis', an analytical framework to be applied to police organisations globally, and other organisational contexts outside policing, in the study of the relationship between authority and leadership.

We have seen the prioritisation of quantitative methods in evidence base policing policy as the 'gold standard' of police research (Lumsden and Goode,2018). Qualitative explorations, which pay attention to the importance of context, are neglected. Approaching the study of police leadership from a social constructionist perspective, this paper contributes to the emerging qualitative evidence base and facilitates greater appreciation of the value of qualitative research in police leadership studies.

The Situated Authority Model provides an important counter-narrative to the invisibility of rank in dominant discourse. The Model furthers the understanding of the nuanced relationship between authority and leadership and provides a framework to support police leaders to critically reflect on their power and their leadership. Further research to explore the application of the Model to different organisational settings and occupational groups in the police, such as variation by gender, and different 
organisational contexts outside policing, is recommended. As police organisations across the globe seek to move beyond an over-reliance on rank towards shared leadership practices, this paper therefore provides a unique critical appreciation of the way authority is experienced and enacted in a disciplined and hierarchical environment.

\section{References}

Adlam, R. (2002) 'Governmental Rationalities in Police Leadership: An Essay Exploring some of the 'Deep Structure' in Police Leadership Praxis' Policing and Society 12(1): 15-36

Adlam, R. (2003) 'Nice People, Big Questions, Heritage Concepts' in R. Adlam and P. Villiers (eds.) 'Police Leadership in the Twenty-First Century: Philosophy, Doctrine and Developments' Hampshire: Waterside Press, pp.34-55

Agar, M. H. (2008) 'The Professional Stranger' Second Edition. Bingley: Emerald Publishing.

Alvesson, M. (1992). 'Leadership as Social Integrative Action: A Study of a Computer Consultancy Company.' Organization Studies 13(2): 185-209.

Alvesson, M. and Sveningsson, S. (2003) 'The Great Disappearing Act: Difficulties in Doing “Leadership" The Leadership Quarterly 14(3): 359-381.

Andersson, T. and Tengblad, S. (2009) 'When Complexity Meets Culture: New Public Management and the Swedish Police.' Qualitative Research in Accounting \& Management 6(1/2): 41-56.

Becker, H. (1970) 'Practitioners of Vice and Crime' in R.W. Habenstein (ed.)

'Pathways to Data' Chicago: Aldine.

Biggart, N. W. and Hamilton, G. G. (1987) 'An Institutional Theory of Leadership.' The Journal of Applied Behavioral Science 23(4): 429-441.

Blumer, H. (1969) 'Symbolic Interactionism: Perspective and Method' (Second Edition) Edition Berkley: University of California Press

Brown, J. (1996) 'Police Research: Some Critical Issues' in F. Leishman, B. Loveday and S.P. Savage (eds.) ‘Core Issues in Policing’ London: Longman, pp.177-190

Bryman, A.; Stephens, M. and a Campo, C. (1996) 'The Importance of Context: Qualitative Research and the Study of Leadership.’ The Leadership Quarterly 7(3): $353-370$. 
Bullock, K. (2018) '(Re)presenting 'order' online: the construction of police presentational strategies on social media' Policing and Society 28(3): 345-359

Bullock, K. and Garland, J. (2018) Police officers, mental (ill-)health and spoiled identity' Criminology \& Criminal Justice 18(2):173-189

Burns, J. M. (1978) 'Leadership. ’ New York: Harper Perennial Political Classics.

Caless, B. and Owens, J. (2016) 'Police and Crime Commissioners: The Transformation of Police Accountability' Bristol: Policy Press.

Caless, B. and Tong, S. (2015) 'Leading Policing in Europe: An Empirical Study of Strategic Police Leadership’ Bristol: Policy Press

Carson, J., Tesluk, P., and Marrone, J. (2007). 'Shared Leadership in Teams: An Investigation of Antecedent Conditions and Performance.' Academy of Management Journal 50(5): 1217-1234.

Chan, J. (2007) 'Making Sense of Police Reforms' Theoretical Criminology 11(3): 323343

Chaleff, I. (2009) 'The Courageous Follower' San Francisco: Berrett-Koehler

Charmaz, K. (2014) ‘Constructing Grounded Theory’ Second Edition. London: Sage Publications.

Cockcroft, T. (2007) 'Police Culture(s): Some Definitional, Methodological and Analytical Considerations' in M. O'Neill, M. Marks and A. M. Singh (eds.) 'Police Occupational Culture: New Debates and Directions' Oxford: Elsevier JAI, pp. 85-102

Cockcroft, T. (2014) 'Police Culture and Transformational Leadership: Outlining the Contours of a Troubled Relationship' Policing: A Journal of Policy and Practice 8(1): 5-13.

Collinson, D. (2006) 'Rethinking Followership: A Post-Structuralist Analysis of Follower Identities.' The Leadership Quarterly 17(2): 179-189.

Collinson, D. (2011) 'Critical Leadership Studies' in A. Bryman, D. Collinson, K. Grint, B. Jackson and M. Uhl-Bien (eds.) 'The Sage Handbook of Leadership'. London: Sage Publications, pp.181-194

Collinson, D. (2012) 'Prozac Leadership and the Limits of Positive Thinking' Leadership 8(2): 87-107

Collinson, D. (2014) 'Dichotomies, Dialectics and Dilemmas: New Directions for Critical Leadership Studies?' Leadership 10(1): 36-55. 
Cowper, T. J. (2004) 'The Myth of the 'Military Model' of Leadership in Law Enforcement' in Q. G. Thurman and J. Zhano (eds.) 'Contemporary Policing: Controversies, Challenges and Solutions' California: Roxbury Publishing, pp.113-125

Craig, C.; Marnoch, G. and Topping, I. (2010) 'Shared Leadership with Minority Ethnic Communities: Views from the Police and the Public in the UK.' Policing and Society 20(3): 336-357.

Crevani, L.; Lindgren, M. and Packendorff, J. (2010) 'Leadership, Not Leaders: On the Study of Leadership as Practices and Interactions.' Scandinavian Journal of Management 26(1): 77-86.

Cronbach, L. J. (1975) 'Beyond the Two Disciplines of Scientific Psychology' American Psychologist 30(2): 116-127

Davies, A. and Thomas, R. (2003) 'Talking Cop: Discourses of Change and Policing Identities.' Public Administration 81(4): 41-58.

de Maillard, J. and Savage, S.P. (2018) 'Policing as a Performing Art? The Contradictory Nature of Contemporary Police Performance Management' Criminology and Criminal Justice 18(3): 314-331

de Tribolet-Hardy, F., Kesic, D. and Thomas, S.D.T (2015) 'Police management of mental health crisis situations in the community: status quo, current gaps and future directions' Policing and Society 25(3): 294-307

Donmeyer, R. (2000) 'Generalizability and the Single-Case Study' in R. Gomm, M. Hammersley and P. Foster (eds.) 'Case Study Method: Key Issues, Key Texts' London: Sage Publications, pp.45-68

Fleming, J. (2008) 'Managing the Diary: What Does a Police Commissioner Do?' Public Administration 86(3): 679-698

Fleming, J. (2014) 'The Pursuit of Professionalism: Lessons from Australasia' in J. M. Brown (ed.) 'The Future of Policing' London: Routledge, pp.355-368

Fleming, J. and Lafferty, G. (2000) 'New Management Techniques and Restructuring for Accountability in Australian Police Organisations' Policing: An International Journal of Police Strategies and Management 23(2): 154-168

Fleming, J. and Marks, M. (2004) “As Unremarkable at Air They Breathe'? Reforming Police Management in South Africa' Current Sociology 52(5): 784-808 
Fletcher, J. K. (2004) 'The Paradox of Postheroic Leadership: An Essay on Gender, Power, and Transformational Change.' The Leadership Quarterly 15(5): 647661.

Fletcher, J. K. and Kaufer, K. (2003) 'Shared Leadership: Paradox and Possibility’ C. L. Pearce and J. A. Conger (eds.) 'Shared Leadership: Reframing the Hows and Whys of Leadership'. California: Sage Publications, pp.21-47

Ford, J. (2006) 'Discourses of Leadership: Gender, Identity and Contradiction in a UK Public Sector Organisation.’ Leadership 2(1): 77-99.

Ford, J. (2010) 'Studying Leadership Critically: A Psychosocial Lens on Leadership Identities.' Leadership 6(1): 47-65.

Gardner, J. W. (1990) 'On Leadership’. New York: The Free Press.

Garland, D. (2001) 'The Culture of Control: Crime and Social Order in Contemporary Society' Oxford: Oxford University Press

George, A. L. and Bennett, A. (2005) 'Case Studies and Theory Development in the Social Sciences' Cambridge, MA: MIT Press

Goffman, E. (1959) 'The Presentation of Self in Everyday Life' Garden City: Doubleday Anchor

Gomm, R.; Hammersley, M. and Foster, P. (2000) 'Case Study and Generalisation' in R. Gomm, M. Hammersley and P. Foster (eds.) 'Case Study Method: Key Issues, Key Texts' London: Sage Publications, pp.98-116

Gordon, R. (2002). 'Conceptualizing Leadership with Respect to its HistoricalContextual Antecedents to Power.' The Leadership Quarterly 13(2): 151-167.

Gordon, R. (2010) 'Dispersed Leadership: Exploring the Impact of Antecedent Forms of Power Using a Communicative Framework' Management Communication Quarterly 24(2): 260-287

Gravelle, J. (2014) 'Researching the Police: Personal Insights and Reflections' in J. Gravelle and C. Rogers (eds.) 'Researching the Police in the $21^{\text {st }}$ Century: International Lessons from the Field' Hampshire: Palgrave Macmillan, pp.43-82

Grint, K. (2005) 'Problems, Problems, Problems: The Social Construction of Leadership.' Human Relations 58(11): 1457-1494.

Grint, K. (2010) 'The Cuckoo Clock Syndrome: Addicted to Command, Allergic to Leadership.' European Management Journal 28(4): 306-313.

Gronn, P. (2002) 'Distributed Leadership as a Unit of Analysis' The Leadership Quarterly 13(4): 423-451. 
Haake, U.; Rantatalo, O. and Lindberg, O. (2017) 'Police Leaders Make Poor Change Agents: Leadership Practice in the Face of A Major Organisational Reform' Policing and Society 27(7); 764-778

Hammersley, M. (2012) 'Troubling Theory in Case Study Research' Higher Education Research \& Development 31(3): 393-405

Herrington, V. and Colvin, A. (2016) 'Police Leadership for Complex Times.' Policing 10(1): 7-16.

Hesketh, I., Cooper, C. L. and Ivy, J. (2005) 'Well-Being, Austerity and Policing: Is It Worth Investing in Resilience Training?' The Police Journal 88(3): 220-230

HMIC (2017) 'State of Policing: The Annual Assessment of Policing in England and Wales 2016' London: HMIC

Holdaway, S. (1977) 'Changes in Urban Policing.' British Journal of Sociology 28(2): 119-137.

Holdaway, S. (2017) 'The Re-Professionalization of the Police in England and Wales' Criminology and Criminal Justice 17(5): 588-604

Hosking, D. M. (1997) 'Organizing, Leadership, and Skilful Process'. in K. Grint (ed.) 'Leadership: Classical, Contemporary and Critical Approaches' Oxford: Oxford University Press, pp. 293-318

Kelley, R. (1992) 'The Power of Followership’ New York: Doubleday

Kort, E. D. (2008) 'What, After All, Is Leadership? 'Leadership' and Plural Action.' The Leadership Quarterly 19(4): 409-425.

Kraska, P. B. (2007) 'Militarization and Policing - Its Relevance to $21^{\text {st }}$ Century Police' Policing 1(4): 501-513

Lincoln, Y. S. and Guba, E. G. (2000) 'The Only Generalization is: There is No Generalization' in R. Gomm, M. Hammersley and P. Foster (eds.) 'Case Study Method: Key Issues, Key Texts’ London: Sage Publications, pp. 27-44

Lister, S. (2013) 'The New Politics of the Police: Police and Crime Commissioners and the 'Operational Independence' of the Police.' Policing 7(3): 239-247.

Loftus, B. (2009) 'Police Culture in a Changing World' Oxford: Oxford University Press.

Lumsden, K. and Goode, J. (2018) 'Policing Research and the Rise of the 'EvidenceBase': Police Officer and Staff Understandings of Research, its Implementation and 'What Works'" Sociology 52(4): 813-829 
Mastrofski, S. D. (2002) 'The Romance of Police Leadership' in E. Waring and D. Weisbur (eds.) 'Advances in Criminological Theory Volume 10: Crime and Social Organization' New Jersey: Transaction Publishers, pp.153-196

Meindl, J. R. (1995) 'The Romance of Leadership as a Follower-Centric Theory: A Social Constructionist Approach.' Leadership Quarterly 6(3): 329-341. Mikecz, R. (2012). 'Interviewing Elites: Addressing Methodological Issues.' Qualitative Inquiry 18(6): 482-493.

Niederhoffer, A. (1967) 'Behind the Shield: The Police in Urban Society'. New York: Doubleday \& Company Inc.

Newburn, T. (2012) 'Police and Crime Commissioners: The Americanization of policing or a very British reform?' International Journal of Law, Crime and Justice 40(1): 31-46

Neyroud, P. (2011) 'Review of Police Leadership and Training' London: Home Office.

Norris, C. (1993) 'Some Ethical Considerations on Field-Work with the Police' in D. Hobbs and T. May (eds.) 'Interpreting the Field: Accounts of Ethnography' Oxford: Clarendon Press, pp. 122-143

Pearce, C.L., Conger, J. A. and Locke, E. A. (2008) 'Shared Leadership Theory’ The Leadership Quarterly 19(5) 622-628

Phillips, R. (1998). 'The Politics of History: Some Methodological and Ethical Dilemmas in Elite-Based Research.' British Educational Research Journal 24(1): 5-19.

Punch, M. (1983) 'Officers and Men: Occupational Culture, Inter-Rank Antagonism and the Investigation of Corruption' in M. Punch (ed.) 'Control in the Police Organization'. Cambridge, MA: MIT Press, pp.227-250

Pye, A. (2005) 'Leadership and Organizing: Sensemaking in Action.' Leadership 1(1): $31-49$.

Ostrander, S. A. (1995) "“Surely You're Not in This Just to Be Helpful”: Access, Rapport and Interviews in Three Studies of Elites' in R. Hertz and J. B. Imber (eds.) 'Studying Elites Using Qualitative Methods' California: Sage Publications, pp.133-150

Raelin, J. (2011) 'From Leadership-As-Practice to Leaderful Practice.' Leadership 7(2): 195-211.

Reddin, W. J. (1977) 'An Integration of Leader-Behavior Typologies.' Group \& Organization Management 2(3): 282-295. 
Reuss-Ianni, E. (1983) 'Two Cultures of Policing: Street Cops and Management Cops'. New Jersey: Transaction Publishers.

Richards, D. (1996). 'Elite Interviewing: Approaches and Pitfalls.' Politics 16(3): 199204.

Rogers, C. (2015) 'International Perspectives in Policing: Challenges for 2020' in P. Wankhade and D. Weir (eds.) 'Police Services: Leadership and Management Perspectives' London: Springer, pp.167-172

Rowe, M. (2006) 'Following the Leader: Front-Line Narratives on Police Leadership.' Policing: An International Journal of Police Strategies \& Management 29(4): 757-767.

Rowe, M. (2007) 'Tripping Over Molehills: Ethics and the Ethnography of Police Work' International Journal of Social Research Methodology 10(1): 37-48

Savage, S. P. (2003) 'Tackling Tradition: Reform and Modernization of the British Police' Contemporary Politics 9(2): 171-184

Schofield, J. W. (1993) 'Generalizability of Qualitative Research’ in M. Hammersley (ed.) 'Social Research: Philosophy, Politics and Practice'. London: Sage Publications, pp.200-225

Shamir, B. (2007) 'From Passive Recipients to Active Co-producers: Followers' Roles in the Leadership Process' in B. Shamir, R. Pillai, M. C. Bligh and M. Uhl-Bien (eds.) 'Follower-Centered Perspectives on Leadership: A Tribute to the Memory of James R. Meindl'. Connecticut: Information Age Publishing, pp.ix-xxii

Skogan, W. G. (2008) 'Why Reforms Fail’ Policing and Society 18(1): 23-34.

Silvestri, M. (2011) 'Women in Charge: Policing, Gender and Leadership'. London: Routledge.

Skinns, L., Wooff, A. and Sprawson, A. (2016) 'The ethics of researching the police: Dilemmas and new directions' in M. Brunger, S. Tong and D. Martin (eds.) 'Introduction to Policing Research: Taking Lessons from Practice' London: Routledge, pp. 185-202

Smircich, L. and Morgan, G. (1982) 'Leadership: The Management of Meaning.' The Journal of Applied Behavioral Science 18(3): 257-273.

Smith, J. and Charles, G. (2015) 'Personal Resilience and Policing' in P. Wankhade and D. Weir (eds.) 'Police Services: Leadership and Management Perspectives' London: Springer, pp.129-144

Stake, R. E. (1995) 'The Art of Case Study Research'. California: Sage Publications. 
Steinheider, B. and Wuestewald, T. (2008) 'From the Bottom-Up: Sharing Leadership in a Police Agency.' Police Practice and Research 9(2): 145-163.

Tourish, D. (2013) 'The Dark Side of Transformational Leadership: A Critical Perspective’. London: Routledge.

Tourish, D. (2014) 'Leadership, More or Less? A Processual, Communication Perspective on the Role of Agency in Leadership Theory.' Leadership 10(1): 7998.

Van Maanen, J. (1978) 'On Watching the Watchers' in P. K. Manning and J. Van Maanen (eds.) 'Policing: A View from the Street' California: Goodyear Publishing, pp.309-349

van Dijk, A. and Crofts, N. (2017) 'Law enforcement and public health as an emerging field' Policing and Society 27(3): 261-275

van Dijk, A., Hoogewoning, F. and Punch, M. (2015) 'What Matters in Policing? Change, Values and Leadership in Turbulent Times'. Bristol: Policy Press. Waddington, P. A. J. (1999) ‘Armed and Unarmed Policing' in R. I. Mawby (ed.) 'Policing Across the World' London: UCL Press pp:151-166

Walker, S. and Archbold, C. A. (2014) 'The New World of Police Accountability' Second Edition Los Angeles: Sage.

Weick, K.E. (1995) 'Sensemaking in Organizations' Thousand Oaks: Sage.

Whitchurch, C. (2008) 'Shifting Identities and Blurring Boundaries: The Emergence of Third Space Professionals in UK Higher Education' Higher Education Quarterly 62(4): 377-396

Wood, M. and Ladkin, D. (2008) 'The Event's the Thing: Brief Encounters with the Leaderful Moment' in K. T. James and J. Collins (eds.) 'Leadership Perspectives: Knowledge into Action'. Hampshire: Palgrave Macmillan, pp.1528 